\title{
Oxycodone hydrochloride immediate-release analgesic for managing severe pain: abuse- deterrent formulations
}

This article was published in the following Dove Press journal:

Therapeutics and Clinical Risk Management

\section{AH Kibbe' \\ TS Franko ${ }^{2}$ \\ VM Shah ${ }^{2}$}

'Department of Pharmaceutical Sciences, Nesbitt School of Pharmacy, Wilkes University, Wilkes-Barre, PA, USA; ${ }^{2}$ Department of Clinical Pharmacy, Nesbitt School of Pharmacy, Wilkes University, WilkesBarre, PA, USA
Correspondence: AH Kibbe Department of Pharmaceutical Sciences, Nesbitt School of Pharmacy, Wilkes University, 187 River Street, WilkesBarre, PA 18766, USA

Tel +I 5704084274

Fax + I 5704084299

Email arthur.kibbe@wilkes.edu

\begin{abstract}
This paper is an expert opinion in response to the development of abuse-deterrent immediate-release tablets containing oxycodone $\mathrm{HCl}$. There is a potential impact, both positive and negative, of this type of dosage form on patients, those suffering from the disease of addiction, health care providers, and the cost of health care.
\end{abstract}

Keywords: non-metabolizable polymer, opioids, risk/benefit, IV abuse, nasal abuse

\section{Introduction}

Chronic pain affects countless lives. As of 2011, over 100,000,000 Americans suffered from chronic pain, more than those with diabetes, heart disease, stroke, and cancer combined. Chronic pain costs the health care system 560-635 billion dollars annually, about 2,000 dollars per person living in the USA. ${ }^{1}$

Opioid medications are used as a component in the management of pain. In the USA, about $6.9 \%$ of all adults have used an opioid analgesic in the last 30 days. $^{2}$ Opioid prescribing rates peaked in 2012 with over 255 million prescriptions written in that year. In 2016, the number dropped to a decade low of slightly over 214 million. However, in over a quarter of the counties in the USA, enough prescriptions were written to provide every resident an opioid. ${ }^{3}$

Since the sharp rise of opioid prescribing trends, there has been a corresponding increase in opioid overdoses. More than 64,000 people died from a drug-related overdose death in 2016, over 14,000 of which involved a natural or semi-synthetic opioid. Since 2010, deaths associated with heroin have spiked, with over 15,000 cases reported in 2016 alone. ${ }^{4}$ A correlation exists between opioid use and heroin abuse. About $80 \%$ of the heroin users got their start from a legitimate opioid prescription. ${ }^{5}$ The majority of opioids used for non-medical purposes are obtained freely from friends and family as opposed to purchasing from a street dealer. ${ }^{6}$

Recently, there has been a rise in the use of abuse-deterrent opioids. These products utilize various mechanisms (physical barriers, agonist/antagonist combinations, and delivery systems) to decrease the risk of medication misuse. ${ }^{7}$ There is data on the extended-release forms of the oral solid dosage forms of opioids which indicate that they are not easily converted into an injectable form in low volumes and thus have an inherent drug abuse-deterrent property. ${ }^{8}$ Though the US Food and Drug Administration (FDA) continues to encourage the development of such formulations, the long-term utility of abuse-deterrent medications is contested (Kibbe AK, Report to the FDA advisory panel by the makers of Vantrela ER, personal communication, May, 2017). 
Experts claim that abuse deterrent does not necessarily mean abuse proof. This was seen with the reformulated version of Opana ER (oxymorphone extended-release) tablets. Though designed to prevent nasal inhalation, this medication was easily dissolved and injected leading to a large 2015 HIV outbreak in Indiana. Furthermore, little evidence exists to support the usage of opioid medications for long-term non-malignant pain. ${ }^{9}$ Additionally, a recent report by the Institute for Clinical and Economic Review found that based on the price of abusedeterrent formulations, cost neutrality to the health care system would be impossible to maintain. It is estimated that a $41 \%$ decrease in average price would be necessary to reach neutrality. Examples of cost associated with abuse-deterrent formulations can be seen in the Veteran's Affairs pharmacy expenditures where 100 million dollars was spent on opioids in 2016. A conversion to all abuse-deterrent opioids would increase that number to over one billion dollars. ${ }^{10}$

\section{Discussion Corporate response}

Several companies have responded to the problem of diversion of immediate-release (IR) oral solid dosage forms of oxycodone. They have designed dosage forms that will inhibit the potential abuser from preparing forms of the drug which can be injected or administered intra-nasally. The general approach is to incorporate excipients which will make a viscous gel if the dosage form is mixed with small amounts of water. This makes the administration via an intravenous (IV) injection impossible. They also use excipients which make preparing a fine powder that can be insufflated difficult, if not impossible. The excipients used do not materially interfere with the release of the oxycodone when the tablet is taken orally or evaluated in a standard United States Pharmacopeia dissolution apparatus. Thus, the product can be compared to the IR oxycodone to obtain market approval as if it were a conventional generic form of the product.

In April 2015, the FDA published a Guidance for Industry on Abuse-Deterrent Opioids Evaluation and Labeling ${ }^{13}$ that discusses evaluating route-specific data such as vaporization, syringeability, and particle size distribution (Table 1). There are currently 10 opioids marketed with FDA-approved abusedeterrent labeling. Half of these abuse-deterrent formulations are oxycodone containing products, yet only one of the approved products is an IR oxycodone formulation. No generic abuse-deterrent products are currently available, though in March of 2016 the FDA published an additional Guidance for Industry ${ }^{14}$ to assist in potential interest of applicants. The FDA has held open hearings before an advisory panel which
Table I Currently approved opioids with deterrent labeling

\begin{tabular}{lll}
\hline Brand name & $\begin{array}{l}\text { Active pharmaceutical } \\
\text { ingredient }\end{array}$ & ER or IR \\
\hline Embeda & Morphine & ER \\
MorphaBond ER & Morphine & ER \\
Arymo ER & Morphine & ER \\
Hysingia ER & Hydrocodone & ER \\
Vantrela ER & Hydrocodone & ER \\
OxyContin & Oxycodone & ER \\
Targiniq ER & Oxycodone & ER \\
Xtanpza ER & Oxycodone & ER \\
Troxyca ER & Oxycodone/naltrexone & ER \\
RoxyBond & Oxycodone & IR \\
\hline
\end{tabular}

Notes: Only the last entry is an IR product. Naltrexone is a pure opioid antagonist and is in Troxyca to eliminate the benefits of the opioid if the product is tampered with. Data from opioid medications. ${ }^{12}$

Abbreviations: ER, extended release; IR, immediate release.

discussed the application for approval of opioids with abusedeterrent capability. During these discussions, attended by the primary author as a member of the advisory panel (Kibbe A, FDA Advisory Panel, personal communication, 2017), ${ }^{15}$ the nature of the polymers used to increase viscosity and deter IV and nasal abuse was discussed. ${ }^{16,17}$ The individual polymers are listed in the section "Product characteristics".

\section{Product characteristics}

All of the products that have been submitted for approval with the added designation of abuse deterrent have some common characteristics. They use excipients that are acceptable for use in oral dosage forms and are polymers which will absorb water and form a viscous solution or gel. The three classes of such polymers are cellulose derivatives such as HPMC, polymethacrylates (Eudraget ${ }^{\mathbb{R}}$; Evonik Corp., Parsippany, NJ, USA), and polyethylene oxide (Polyox ${ }^{\circledR}$; Dow Chemical Co. Midland, MI, USA). ${ }^{11}$ The amount of polymer used is sufficient to make a gel when the tablet is dissolved in a small amount of water $(10 \mathrm{~mL})$ but does not form a hydrophilic matrix and thus causes slow release of the oxycodone. Other formulation techniques (some proprietary) are employed to make reduction in tablet size extremely difficult using equipment easily available to the abuser (mortar and pestle, coffee grinder, etc.). In all cases, the finished product will release the active pharmaceutical ingredient (API) rapidly in vivo or in vitro when the volume of dissolving medium is large $(250-900 \mathrm{~mL})$.

The products which have been approved to date have a strong possibility to cause significant damage to an opioid user who has defeated the mechanisms purported to be abuse deterrent. None of the products already approved employ a biodegradable polymer. Should such polymers (listed earlier) 
enter the blood or the lungs, they will remain for a considerable amount of time. The current standard for abuse deterrent is that if a unit dosage form is dissolved in 5-10 $\mathrm{mL}$ of water, it should be too thick to pass through a needle, so called syringeability. However, the current polymers used are indeed water soluble and if sufficiently diluted will form a liquid that will pass through a needle. A patient with substance use disorder conceivably could inject $20-30 \mathrm{~mL}$ of a solution intravenously and thus dose themselves with the opioid and a non-biodegradable polymer. This polymer could collect in capillary beds and have a negative impact on the individual. Furthermore, should the tablets be grounded into a fine powder and insufflated, these water-soluble polymers would coat the lining of the lungs, potentially leading to advanced pulmonary conditions. There is a potential for considerable risk should abuse-deterrent products be misused.

\section{Analysis}

There are a number of groups that are directly or indirectly affected by the development of a dosage form which allows for immediate release of oxycodone $\mathrm{HCl}$ and has characteristics which might inhibit the diversion and illicit use of the API.

\section{The patient}

An individual who has a legitimate need for short-term or chronic administration of IR oxycodone will find no additional benefit from an abuse-deterrent formulation as they will use the drug as instructed.

\section{A physician}

If the physician has no doubt that the patient who has been prescribed the IR oxycodone is truly in need of the relief it provides and is well known to the physician, he/she can safely prescribe the normal IR product. If the patient might be in need but the physician is concerned that some or all of the prescribed medication might be given or sold to another, then the physician might choose to prescribe the abuse-deterrent form of the drug product.

\section{Abuser (addict)}

An individual who has progressed to a chronic opioid abuser and continues to use opioids either by injection or by insufflation will find that the abuse-deterrent products are more difficult to manipulate than the conventional IR products. This in and of itself will not stop them from seeking opioids but rather they might seek other sources of opioids, such as heroin, or develop more sophisticated ways of manipulating the products.

If they do devise a method of dissolving sufficient API from these tablets into a solution that can be injected, they face a secondary threat to their life. The polymers used to make the solution viscous are only approved for oral use as they cannot be metabolized by normal human enzymes. (See the section on safety in the monographs from the Handbook of Pharmaceutical Excipients) Thus, if injected even in small quantities, they represent a real health hazard as they can become lodged in a capillary bed and cause blockage of blood flow in that area. There is no data that has evaluated the safety of these compounds or the limits of exposure when administered IV. ${ }^{18}$ However, in some cases, the limit of exposure for a worker who might inhale the material has been set as $50 \mathrm{ppm}$ in the UK.

\section{Pharmaceutical manufacturer}

The products that fit this category are manufactured using a proprietary manufacturing method, and the cost of these products will be higher than the already available IR products. Due to the high cost of these products, the pharmaceutical industry will heavily market directly to providers. Such marketing techniques may result in increased prescribing habits, passing the cost on to patients for a medication that will not provide improved pain management as compared to other, less costly, oxycodone products that are currently available.

\section{Conclusion}

1. For most patients, a form of IR oxycodone that is abuse deterrent is unnecessary.

2. For abusers, the products can reduce the use of this opioid and cause them to shift to other agents, such as heroin. It will not cause more addicts to seek treatment.

3. Should a method of extraction of the API not previously tested be devised and individuals dose themselves, it will also include some non-metabolizable polymer which can potentially increase the risk of adverse health effects.

4. Diversion of IR oxycodone may go down (this is a strong statement as it assumes that all physicians everywhere will stop writing for normal oxycodone and only prescribe abuse-deterrent formulations). Most patients are not diverters or abusers, but they tend to stockpile medications. This is where the issue lands, especially on overprescribing. This statement, under the current prescribing climate, pertains to people who fake being in pain and appear legitimate and get normal oxycodone up front. 
5. The cost of IR oxycodone will go up.

6. Some manufacturers will make more money.

\section{Disclosure}

The authors report no conflicts of interest in this work.

\section{References}

1. The American Academy of Pain Medicine. AAMP facts and figures on pain. Available from: http://www.painmed.org/patientcenter/facts_on_ pain.aspx. Accessed September 1, 2017.

2. Kenan K, Mack K, Paulozzi L. Trends in prescriptions for oxycodone and other commonly used opioids in the United States, 2000-2010. Open Med. 2012;6(2):e41-e47.

3. Center for Disease Control and Prevention. US prescribing rate maps. Opioid overdose [updated July 31, 2017]. Available from: https:// www.cdc.gov/drugoverdose/maps/rxrate-maps.html. Accessed September 1, 2017.

4. National Institute on Drug Abuse. Overdose death rates [updated September 2017]. Available from: https://www.drugabuse.gov/related-topics/ trends-statistics/overdose-death-rates. Accessed September 14, 2017.

5. National Institute on Drug Abuse. Prescription opioid use is a risk factor for heroin use. Prescription opioids and heroin [updated December 2015]. Available from: https://www.drugabuse.gov/ publications/research-reports/relationship-between-prescription-drugheroin-abuse/prescription-opioid-use-risk-factor-heroin-use. Accessed September 20, 2017.

6. Center for Disease Control and Prevention. Prescribing data [updated August 30, 2017]. Available from: https://www.cdc.gov/drugoverdose/ data/prescribing.html. Accessed September 20, 2017.

7. National Institute on Drug Abuse. How can prescription drug misuse be prevented? Misuse of prescription drugs [updated August 2016]. Available from: https://www.drugabuse.gov/publications/researchreports/misuse-prescription-drugs/how-can-prescription-drug-misusebe-prevented. Accessed September 20, 2017.

8. Mezher M. FDA to take closer look at abuse-deterrent opioids. Regulatory Affairs Professionals Society [updated June 13, 2017]. Available from: http://www.raps.org/Regulatory-Focus/News/2017/06/13/27895/ FDA-to-Take-Closer-Look-at-Abuse-Deterrent-Opioids/. Accessed September 20, 2017.
9. Becker W, Fiellin D. Abuse-deterent opioid formulations - putting the potential benefits into perspective. N Engl J Med. 2017;376(22): 2103-2105.

10. Banken R, Agboola F, Synnopt P, et al. Abuse-deterent formulations of opioids: effectiveness and value. Institute for Clinical and Economic Review [updated August 8, 2017]. Available from: https:// icer-review.org/wp-content/uploads/2016/08/NECEPAC_ADF_Final_ Report_08_08_17.pdf. Accessed September 2017.

11. Rowe RC, Sheskey PJ, Cook WG, Fenton ME. Handbook of Pharmaceutical Excipients. 7th ed. Pharmaceutical Press and American Pharmacist Association. London: Royal Pharmaceutical Society; 2012.

12. Opioid medications [updated September 28, 2017]. Available from: https://www.fda.gov/Drugs/DrugSafety/InformationbyDrugClass/ ucm337066.htm. Accessed October 2, 2017.

13. FDA Guidance for Industry. Abuse-deterrent opioids - evaluation and labeling. 2015. Available from: https://www.fda.gov/downloads/ Drugs/GuidanceComplianceRegulatoryInformation/Guidances/ UCM334743.pdf. Accessed January 5, 2018.

14. FDA Draft Guidance for Industry. General Principles for evaluating the abuse deterrence of generic solid oral opioid drug products. 2016. Available from: https://www.fda.gov/downloads/Drugs/GuidanceComplianceRegulatoryInformation/Guidances/UCM492172.pdf. Accessed January 5, 2018.

15. April 5, 2017 AADPAC - likely most relevant. Available from: https://www.fda.gov/AdvisoryCommittees/Calendar/ucm546576.htm. Accessed January 5, 2018.

16. BriefingDocs. Available from: https://www.fda.gov/AdvisoryCommittees/CommitteesMeetingMaterials/Drugs/AnestheticAndAnalgesicDrugProductsAdvisoryCommittee/ucm550016.htm. Accessed January 5, 2018.

17. Transcript. Available from: https://www.fda.gov/downloads/AdvisoryCommittees/CommitteesMeetingMaterials/Drugs/AnestheticAndAnalgesicDrugProductsAdvisoryCommittee/UCM564514.pdf. Accessed January 5, 2018.

18. Sheskey PJ, Cook WC, Cable CG, editors. Handbook of Pharmaceutical Excipient. 8th ed. London: Pharmaceutical Press; 2017:468-472, 707-709, 711-718.
Therapeutics and Clinical Risk Management

\section{Publish your work in this journal}

Therapeutics and Clinical Risk Management is an international, peerreviewed journal of clinical therapeutics and risk management, focusing on concise rapid reporting of clinical studies in all therapeutic areas, outcomes, safety, and programs for the effective, safe, and sustained use of medicines. This journal is indexed on PubMed Central, CAS,

\section{Dovepress}

EMBase, Scopus and the Elsevier Bibliographic databases. The manuscript management system is completely online and includes a very quick and fair peer-review system, which is all easy to use. Visit http://www.dovepress.com/testimonials.php to read real quotes from published authors. 